\title{
Effects of Body Fat and Dominant Somatotype on Explosive Strength and Aerobic Capacity Trainability in Prepubescent Children
}

\author{
Carlos C. Marta, ${ }^{1,2}$ Daniel A. Marinho, ${ }^{2,3}$ Tiago M. Barbosa, ${ }^{2,4}$ André L. Carneiro, ${ }^{2,5}$ \\ Mikel Izquierdo, ${ }^{6}$ ANd Mário C. MARques ${ }^{2,3}$ \\ ${ }^{1}$ Department of Sport Sciences, Polytechnic Institute of Guarda (IPG), Guarda, Portugal; ${ }^{2}$ Research Center in Sports, Health \\ and Human Development (CIDESD), Covilhã, Portugal; ${ }^{3}$ Department of Sport Sciences, University of Beira Interior (UBI), \\ Covilhã, Portugal; ${ }^{4}$ Department of Sport Sciences, Polytechnic Institute of Bragança, Bragança, Portugal; ${ }^{5}$ Department of Sport \\ Sciences, University of Montes Claros-Unimontes, Montes Claros, Brazil; and ${ }^{6}$ Department of Health Sciences, Public \\ University of Navarre, Navarre, Spain
}

\begin{abstract}
Marta, CC, Marinho, DA, Barbosa, TM, Carneiro, AL, Izquierdo, M, and Marques, MC. Effects of body fat and dominant somatotype on explosive strength and aerobic capacity trainability in prepubescent children. J Strength Cond Res 27(12): 3233-3244, 2013-The purpose of this study was to analyze the influence of body fat and somatotype on explosive strength and aerobic capacity trainability in the prepubertal growth spurt, marked by rapid changes in body size, shape, and composition, all of which are sexually dimorphic. One hundred twenty-five healthy children (58 boys, 67 girls), aged 10-11 years (10.8 \pm 0.4 years), who were self-assessed in Tanner stages 1-2, were randomly assigned into 2 experimental groups to train twice a week for 8 weeks: strength training group (19 boys, 22 girls), endurance training group ( 21 boys, 24 girls), and a control group (18 boys, 21 girls). Evaluation of body fat was carried out using the method described by Slaughter. Somatotype was computed according to the Heath-Carter method. Increased endomorphy reduced the likelihood of vertical jump height improvement (odds ratio [OR], $0.10 ; 95 \%$ confidence interval [Cl], 0.01-0.85), increased mesomorphy (OR, 6.15; 95\% Cl, 1.52-24.88) and ectomorphy (OR, 6.52; 95\% Cl, 1.71-24.91) increased the likelihood of sprint performance, and increased ectomorphy (OR, 3.84; $95 \% \mathrm{Cl}, 1.20-12.27)$ increased the likelihood of aerobic fitness gains. Sex did not affect the training-induced changes in strength or aerobic fitness. These data suggest that somatotype has an effect on explosive strength and aerobic capacity trainability, which should not be disregarded. The effect of adiposity on explosive strength, musculoskeletal magnitude on running
\end{abstract}

Address correspondence to Mikel Izquierdo, mikel.izquierdo@gmail. com.

27(12)/3233-3244

Journal of Strength and Conditioning Research

(c) 2013 National Strength and Conditioning Association speed, and relative linearity on running speed and aerobic capacity seem to be crucial factors related to training-induced gains in prepubescent boys and girls.

KEY WoRDS school, intervention, power, endurance, physical fitness, coaching

\section{INTRODUCTION}

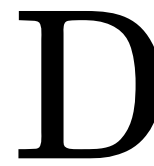

uring the past decade, physical activity participation among young people has decreased considerably and is now below the World Health Organization (WHO) recommendations for health status and well-being (40). Additionally, secular trends in physical fitness revealed a decrease in the performance on several physical fitness tests (26). Many children and adolescents are only exposed to vigorous physical activity during school-based physical education classes (7), and the majority of them do not participate in any organized physical activity during nonschool hours (3). Thus, it is important to ensure that during these classes students are exposed to physical activities that promote health-related physical fitness development and an active lifestyle. School seems to provide an excellent setting to promote physical activity and enhance physical fitness levels (36) by implementing training programs (24). Low aerobic capacity is associated with cardiovascular disease risk factors in children (2); therefore, a great deal of research has focused on activities that enhance cardiorespiratory fitness, disregarding, for instance, neuromotor fitness and muscular strength (4). However, strength training for youth has been recognized as a safe and effective component of youth fitness programs, health promotion objectives, and injury prevention (11). Improvements in muscular fitness and speed/agility can also have a positive effect on skeletal health (30); thus, the inclusion of both aerobic and muscular fitness components within a school-based training program is highly desirable (37). 
Faigenbaum et al. (11) identified several factors that need consideration to maximize the benefits of training in children and adolescents, which include the program design, appropriate supervision, instruction quality and control learning, gender, age, and maturity. Regardless of these items, individual physical characteristics (e.g., body composition and somatotype) could also influence training-induced adaptations. According to Marshall and Tanner (25), peak height velocity (the greatest rate of height increase) and pubertal growth spurt occur at pubic hair stages $3-4$ in boys, but might occur slightly earlier in girls $(\sim$ Tanner stage 3$)$. The children analyzed in this study, aged $10-11$ years and located in Tanner stages 1-2, are considered prepubescent (21), designated in some studies as "early adolescents" (10). During this developmental stage, which precedes peak height velocity, the children show very great growth (about $20 \%$ of adult height), with large metabolic costs, which lead to a decrease in the general resistance of the body (21). At this period, the growth and the great dimensional increase are not accompanied by muscle development because the effects of circulating androgens, particularly testosterone, only manifest themselves at puberty (32), which confers on the child a degree of weakness and hypotonia (21). Also, there is marked increase in subcutaneous adipose tissue during this

TABLE 1. Training program design. ${ }^{\star}$

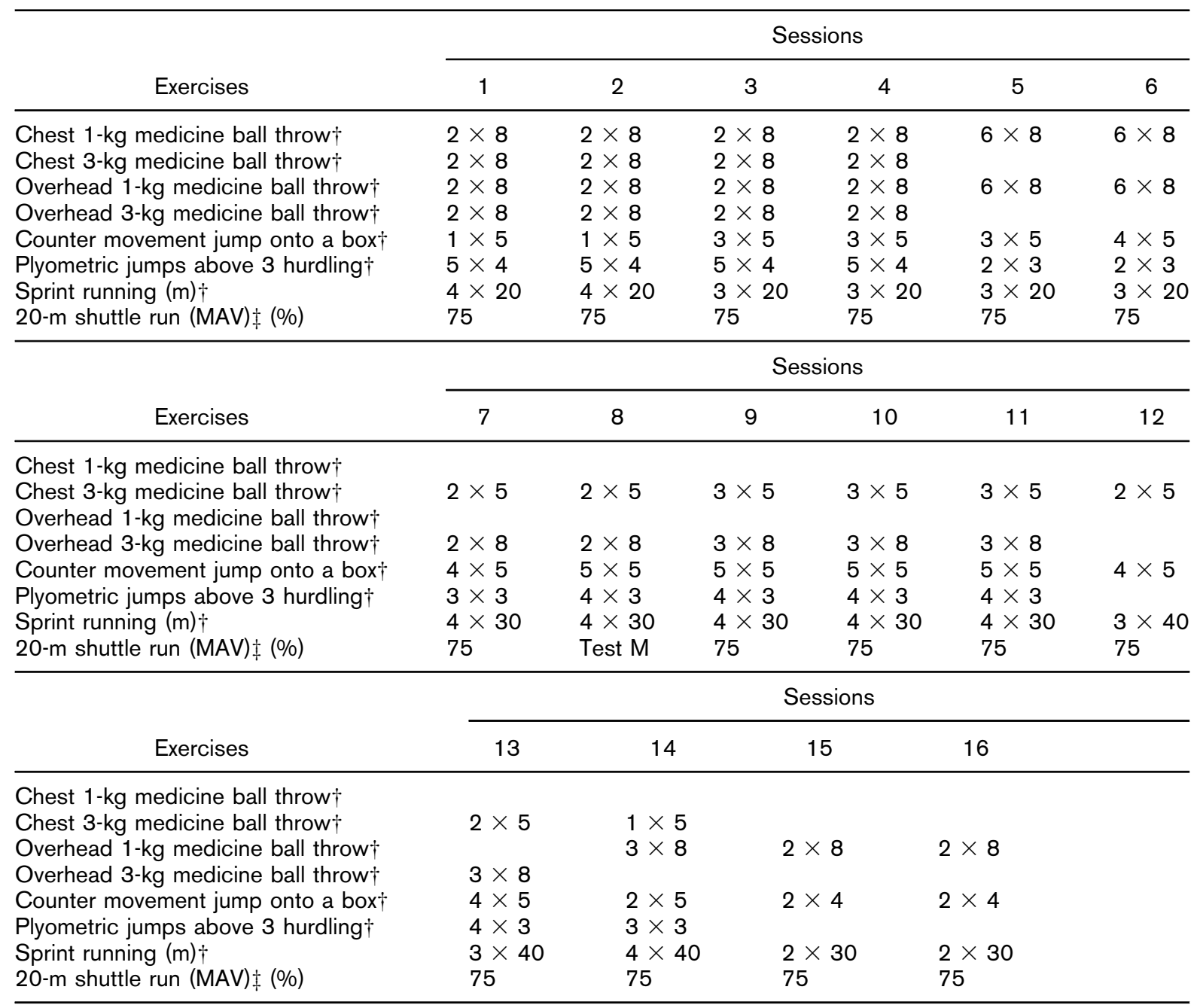

*For the medicine ball throwing and jump onto box, the first number corresponds to sets and second corresponds to repetitions. For sprint running, first number corresponds to sets and second corresponds to the distance to run. For 20-m shuttle run training, each children ran each session (until test M) $75 \%$ of maximum individual aerobic volume performed on pretest and after this test $\mathrm{M}$ moment until program end, ran $75 \%$ of maximum individual aerobic volume performed on test M. MAV = maximum individual aerobic volume. † Power strength training protocol (SG).

$\ddagger$ Endurance training protocol (EG). 
TABLE 2. Descriptive data of anthropometric and morphological parameters and physical performance measures in pretest condition: boys and girls (mean $\pm S D)$.*

\begin{tabular}{|c|c|c|c|c|c|c|}
\hline & \multicolumn{3}{|c|}{ Boys } & \multicolumn{3}{|c|}{ Girls } \\
\hline & CG & SG & EG & CG & SG & EG \\
\hline Decimal age $(y)$ & $10.8 \pm 0.5$ & $10.7 \pm 0.4$ & $10.7 \pm 0.5$ & $10.9 \pm 0.4$ & $10.8 \pm 0.4$ & $10.75 \pm 0.4$ \\
\hline Body height $(\mathrm{cm})$ & $139.5 \pm 7.0$ & $141.6 \pm 5.9$ & $146.7 \pm 8.3$ & $140.8 \pm 6.3$ & $144.8 \pm 8.0$ & $142.7 \pm 7.2$ \\
\hline Body mass (kg) & $37.8 \pm 7.6$ & $38.9 \pm 10.7$ & $42.0 \pm 9.0$ & $37.4 \pm 6.9$ & $41.3 \pm 9.8$ & $39.7 \pm 9.4$ \\
\hline Body fat $(\%)$ & $21.0 \pm 8.0$ & $20.7 \pm 9.0$ & $20.27 \pm 8.4$ & $21.9 \pm 6.1$ & $24.0 \pm 6.1$ & $24.6 \pm 7.6$ \\
\hline Endomorphic & $3.36 \pm 1.7$ & $3.25 \pm 1.7$ & $3.11 \pm 1.6$ & $3.64 \pm 1.4$ & $4.06 \pm 1.3$ & $4.11 \pm 1.6$ \\
\hline Mesomorphic & $4.92 \pm 1.1$ & $4.52 \pm 0.9$ & $4.43 \pm 0.7$ & $3.95 \pm 0.9$ & $4.16 \pm 0.9$ & $4.30 \pm 0.9$ \\
\hline Ectomorphic & $2.21 \pm 1.4$ & $2.43 \pm 1.4$ & $2.54 \pm 1.1$ & $2.44 \pm 1.3$ & $2.40 \pm 1.3$ & $2.41 \pm 1.5$ \\
\hline Counter movement jump (cm) & $23.4 \pm 5.2$ & $22.5 \pm 5.6$ & & $21.0 \pm 3.8$ & $20.2 \pm 2.8$ & \\
\hline Standing long jump (cm) & $140.1 \pm 21.9$ & $129.6 \pm 14.6$ & & $127.9 \pm 15.6$ & $120.3 \pm 10.1$ & \\
\hline $1-\mathrm{kg}$ medicine ball throw $(\mathrm{cm})$ & $375.3 \pm 74.5$ & $367.5 \pm 65.6$ & & $353.1 \pm 35.2$ & $330.7 \pm 49.5$ & \\
\hline 3-kg medicine ball throw $(\mathrm{cm})$ & $233.2 \pm 44.5$ & $231.5 \pm 39.0$ & & $221.0 \pm 37.6$ & $217.5 \pm 38.5$ & \\
\hline 20-m sprint $(\mathrm{s})$ & $4.37 \pm 0.2$ & $4.30 \pm 0.2$ & & $4.38 \pm 0.2$ & $4.43 \pm 0.1$ & \\
\hline$\dot{\mathrm{V}}_{2} \max \left(\mathrm{ml} \cdot \mathrm{kg}^{-1} \cdot \mathrm{min}^{-1}\right)$ & $45.2 \pm 3.9$ & & $45.9 \pm 3.3$ & $44.1 \pm 2.8$ & & $43.0 \pm 2.6$ \\
\hline
\end{tabular}

${ }^{*} \mathrm{CG}=$ control group; $\mathrm{SG}=$ strength training group; $\mathrm{EG}=$ endurance training group.

period, which is greater in the trunk than in the limbs, and more pronounced in girls (21).

Thus, it seems relevant to analyze, in the age group studied, characterized by rapid changes in child development, the effect of body fat, which represents an inert load, noncontributive, associated with an increased metabolic cost (28), and somatotype, which expresses genetic determinism, observed from the morpho-constitutional point of view (21), on training-induced strength and aerobic gains. An analysis of changes in morphological typology of children during growth shows that in prepuberty boys tend to

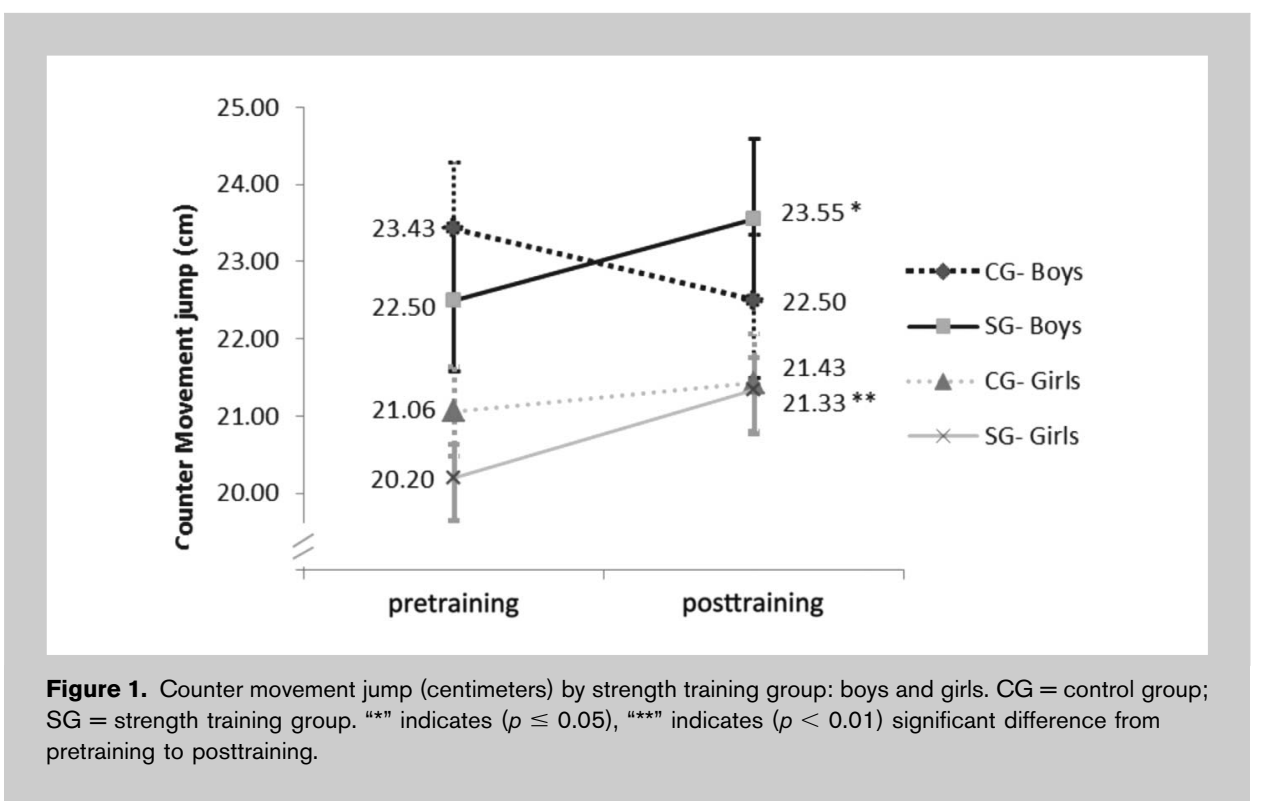

show a slight increase of the mesomorphic (relative muscleskeletal magnitude) values, and girls show an increase of the endomorphic (relative adiposity) and a slight reduction of the ectomorphic (relative thinness) values (22). These factors may influence the execution of the planned exercises, training intensity, and recovery of the performers, resulting in different effects of applying a particular training program. Additionally, both body fat and somatotype are significantly associated with the level of physical fitness achieved $(9,15)$ and appears to influence the development of a training program in children and adolescents (11). Moreover, according to Ignjatovic et al. (14), it would be logical to assume that young people who are stronger and more powerful would have an advantage with regard to strength training, so it will be interesting to verify this presupposition, given that during preadolescence the neural adaptations are those primarily responsible for training-induced strength gains (32).

The purpose of the present study was to analyze the influence of body fat and somatotype on the training of explosive strength and endurance in prepubescent children. It was hypothesized that during this dynamic period of development, marked by rapid changes 


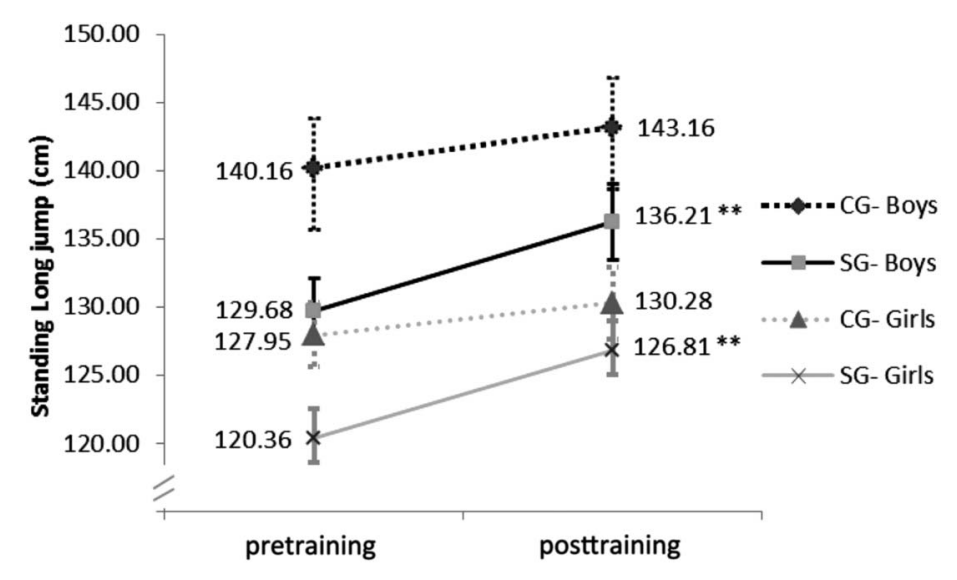

Figure 2. Standing long jump (centimeters) by strength training group: boys and girls. $C G=$ control group; $S G=$ strength training group. "**" indicates $(p<0.01)$ significant difference from pretrainingto posttraining.

effects of growth, only children who were self-assessed as being in Tanner stages 1-2 were selected for the sample.

From the initial sample of 151 students who fulfilled the inclusion criteria, only 134 volunteered to participate. Groups were determined using a random number generator ( $\mathrm{R}$ Foundation for Statistical Computing version 2.14, Vienna, Austria) and resulted in the following assignments: strength group: 20 boys and 24 girls; endurance group: 25 boys and 26 girls; and control group: 18 boys and 21 girls. This procedure was established in accordance with the "CONSORT" statement

in body size, shape, and composition, all of which are sexually dimorphic, both somatotype and body composition would have an effect on training-induced strength and endurance adaptations in untrained prepubescent boys and girls.

\section{Methods}

\section{Experimental Approach to the Problem}

A randomized controlled trial was conducted at the Santa Clara school cluster (Guarda, Portugal). Inclusion criteria were children aged $10-11.5$ years (fifth and sixth graders), with no chronic pediatric diseases or orthopedic limitations, performing no regular oriented extracurricular physical activity (e.g., practicing sport at a club). To minimize the

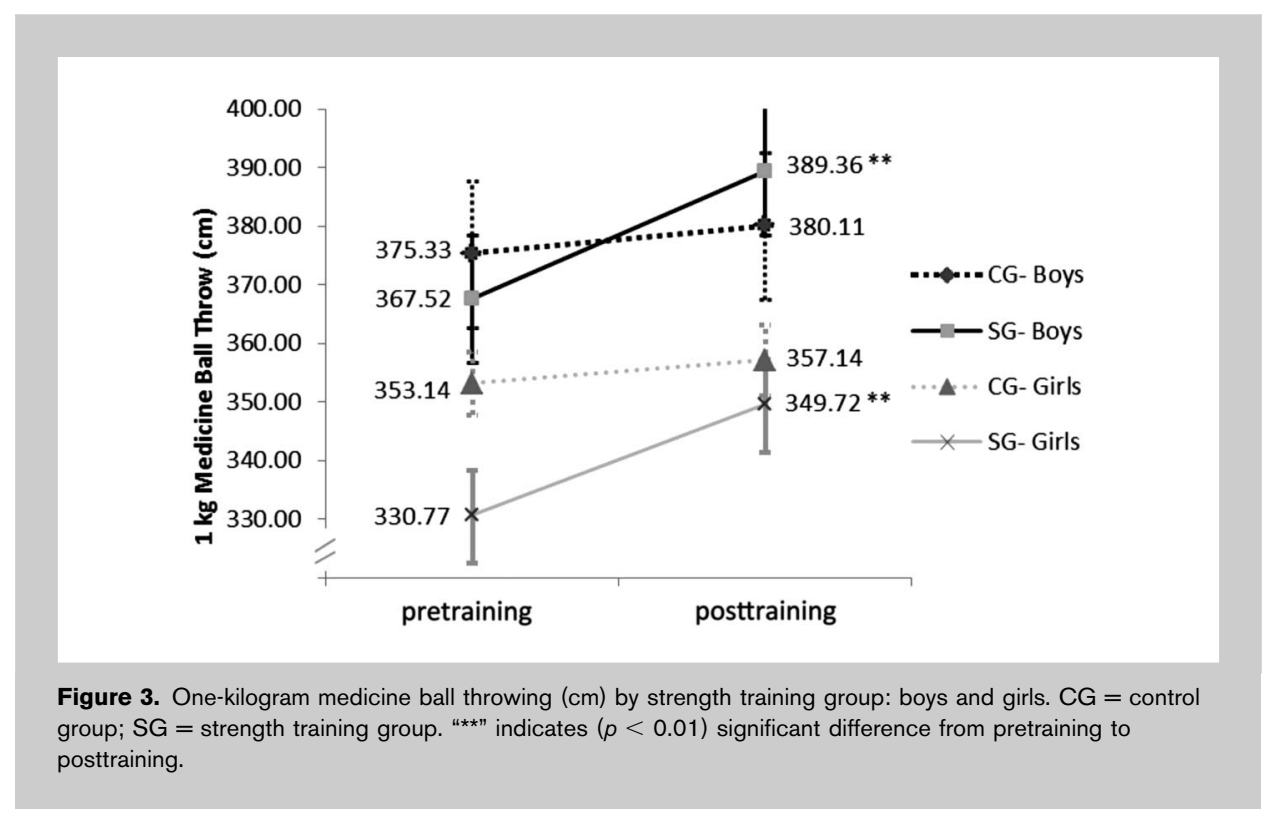

(http://www.consort-statement.org/). The proportion of participants successfully completing the protocol was $93 \%$ (strength training), 88\% (endurance training), and 100\% (control group). Thus, analysis was conducted on the remaining 125 children (strength training: 19 boys and 22 girls; endurance training: 21 boys and 24 girls; and control group: 18 boys and 21 girls, which followed the physical education classes curriculum, without a training program). In Portugal, a physical education class has a set of 45 minutes and another set of 90 minutes twice a week. Typical physical education classes include various activities, in which boys and girls participate simultaneously, with a clear pedagogical focus, but mainly for the purpose of promoting levels of physical activity and physical fitness of students. Usually, these classes start with jogging run during 10 minutes to general warm-up, proceed to joint mobilization and general stretches. After that the class is divided into 2 or 3 proficiency level groups to start the main activities/sports of the class.

Before training, subjects warmed up for approximately 10 minutes with low to moderate intensity exercises (e.g., running, stretching, and joint specific movements). Joint rotations included slow circular movements, both clockwise and counterclockwise, until the entire joint seems to move smoothly. Stretching exercises included back and chest, shoulders, and side stretch, as well as 


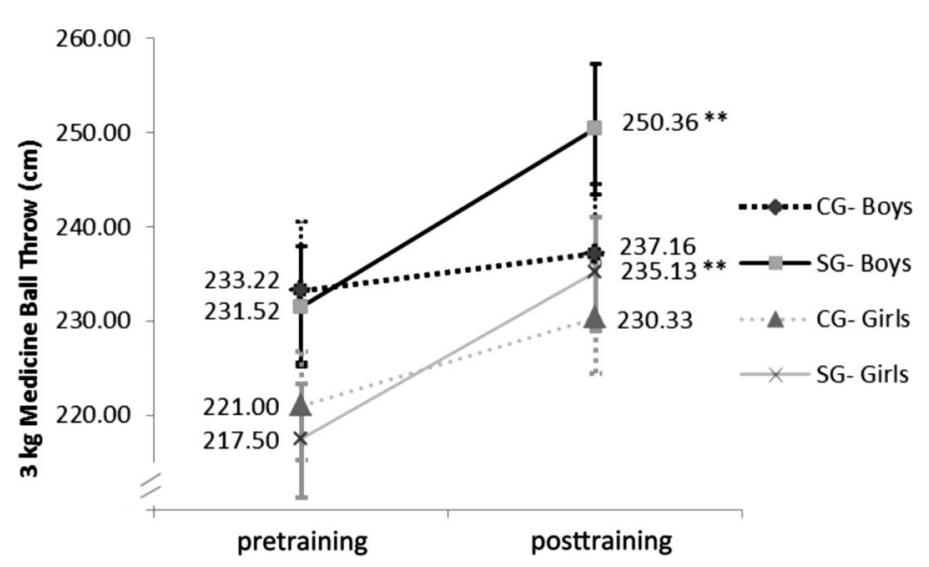

Figure 4. Three-kilograms medicine ball throwing $(\mathrm{cm})$ by strength training group: boys and girls. $\mathrm{CG}=\mathrm{control}$ group; $\mathrm{SG}=$ strength training group. "**" indicates $(p<0.01)$ significant difference from pretrainingto posttraining. quadriceps, calf, groin, and hamstring stretches. At the end of the training sessions, subjects performed 5 minutes of static stretching exercises. After the warm-up, the strength group performed an explosive strength training program comprising upper body (1- and 3-kg medicine ball throws) and lower body (jumps onto a box and hurdle jumps, from 0.3 to $0.5 \mathrm{~m}$ ) plyometric exercises, as well as a speed drill (sets of 20- to 40$\mathrm{m}$ speed runs). This type of exercises enables the muscles to achieve maximum force in the shortest possible time interval and is used by most coaches in workout routines as a way of increasing explosive power (6). Chu et al. (6) are of the opinion that plyometric training is more effective in the production of power than other types of exercise. This type of

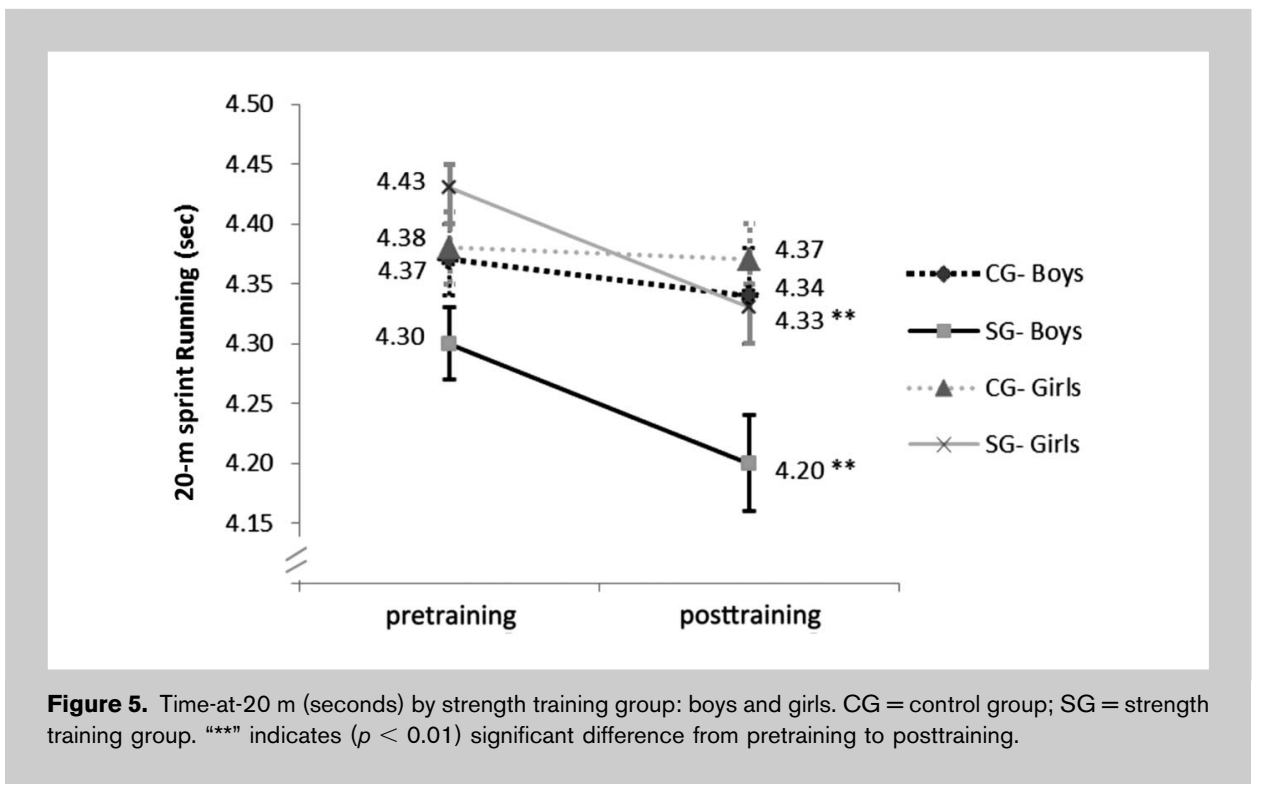

training is believed to prepare the neuromuscular system for the demands of strength training by activating additional neural pathways and enhancing the neuromuscular system to achieve a greater degree of readiness (19) and is safe and effective for prepubertal children provided that age-appropriate training guidelines are followed (16). The endurance group performed 20-m shuttle run exercise. This endurance task was developed based on an individual training volume-set to about $75 \%$ of the established maximum aerobic volume achieved on a previous test. After 4 weeks of training, endurance group subjects were reassessed using 20-m shuttle run tests to readjust the volume and intensity of the $20-\mathrm{m}$ shuttle run exercise. Each session lasted approximately 45 minutes (strength training) and 20 minutes (endurance training). The rest period between sets was 1 minute and between exercises was 2 minutes. Before the start of the training, subjects completed 2 familiarization sessions to practice the drill and routines they would further perform during the training period (i.e., power training exercises and 20-m shuttle run test). During this time, the children were taught about the proper technique on each training exercise, and any of their questions were properly answered to clear out any doubts. In the course of conducting training, there was a constant concern to ensure the necessary security and maintenance of safe hydration levels, as well as to encourage all children to do their best to achieve the best results. Clear instructions about the importance of adequate nutrition were also delivered. All measurements were made in the morning, 3 hours after breakfast. Training programs were also conducted 3 hours after meals. The instructor-to-child ratio was $1: 11$, slightly above the limit recommended by Faigenbaum et al. (12) (1:10). However, free weights or weight/hydraulic machines were not used in the training, but only medicine balls and body weight exercises, which facilitated the supervision process. The same researcher conducted the training program and the anthropometric and 


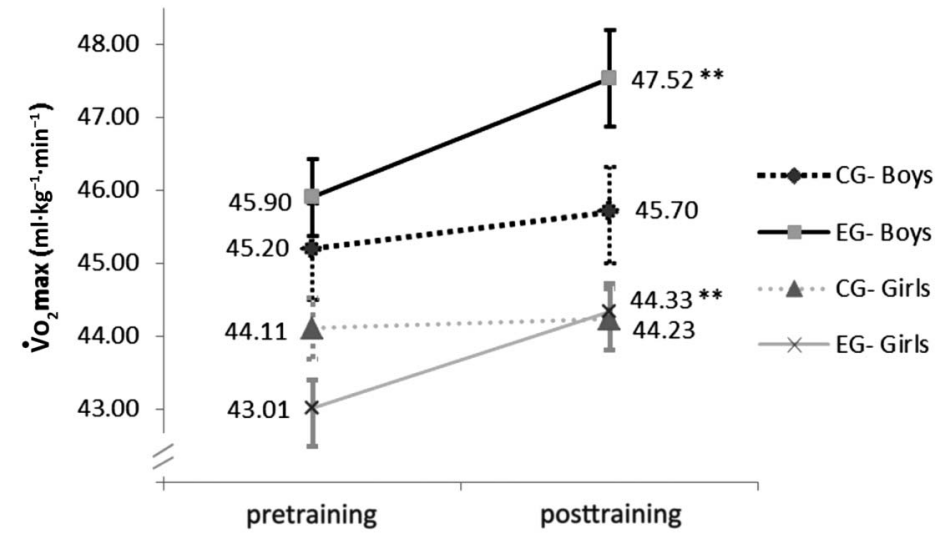

Figure 6. $\dot{V}_{2} \max \left(\mathrm{ml} \cdot \mathrm{kg}^{-1} \cdot \mathrm{min}^{-1}\right)$ by endurance training group: boys and girls. $\mathrm{CG}=$ control group; $\mathrm{EG}=$ endurance training group. "**" indicates $(p<0.01)$ significant difference from pretraining to posttraining.

problems, physical limitations, physical activity habits, and training experiences for the past 6 months. The selected children were in the Tanner stages 1-2 (boys: stage 1, $81 \%$ and stage 2, 19\%; girls: stage 1 , $53.7 \%$ and stage $2,46.3 \%$ ). No subject had regularly participated in any form of strength training program before this experiment. Subjects were carefully informed about the design of the study, and subsequently the children's parents signed an informed consent document before the start of the study. The study was conducted according to the declaration of Helsinki and was

physical fitness assessments. Throughout pre- and experimental periods, the subjects reported their non-involvement in additional regular exercise programs for developing or maintaining strength and endurance performance. There were no injuries resulting from the implementation of the training programs. A more detailed analysis of the program can be found in Table 1 .

\section{Subjects}

Prepubescent children $(n=125)$, aged $10-11.5$ years, all of whom volunteered for this study. Before data collection and the start of the training, each participant reported any health approved by the institutional review boards of the University of Beira Interior (UBI) and Research Centre in Sports, Health and Human Development (CIDESD), Portugal. Anthropometric and morphological parameters and physical performance measures were evaluated for all subjects in pretest (Table 2).

\section{Procedures}

Anthropometric and Morphological Measurements. All anthropometric measurements were assessed according to international standards for anthropometric assessment (23) and were carried out before any physical performance test. The

TABLE 3. Strength gains: Odds ratio of logistic regressions ( $95 \%$ confidence interval). $\dagger$

\begin{tabular}{|c|c|c|c|c|c|}
\hline & CM jump & SL jump & $1-\mathrm{kg}$ ball throw & 3-kg ball throw & 20-m sprint \\
\hline Girlsł & $2.95(0.91-9.60)$ & $1.33(0.28-6.39)$ & $1.12(0.23-5.52)$ & $0.36(0.07-1.82)$ & $4.41(0.78-24.87)$ \\
\hline$\% B F$ & $1.47(0.94-2.29)$ & $1.39(0.78-2.48)$ & $0.82(0.43-1.58)$ & $0.67(0.36-1.23)$ & $1.47(0.77-2.79)$ \\
\hline END & $0.10(0.01-0.85)^{*}$ & $0.15(0.01-2.23)$ & $3.32(0.16-67.55)$ & $8.05(0.49-133.43)$ & $0.11(0.01-2.11)$ \\
\hline MES & $2.08(0.87-4.99)$ & $1.30(0.40-4.20)$ & $0.98(0.29-3.35)$ & $0.9(0.27-3.03)$ & $6.15(1.52-24.88)^{*}$ \\
\hline ECT & $1.08(0.49-2.34)$ & $2.33(0.81-6.73)$ & $0.43(0.15-1.28)$ & $0.63(0.22-1.82)$ & $6.52(1.71-24.91)^{\star \star}$ \\
\hline SG§ & 1.33 (0.50-3.53) & $11.72(2.55-53.8)^{\star \star}$ & $23.82(4.46-127.0)^{\star \star}$ & $53.01(9.96-281.9)^{\star \star}$ & $61.98(7.47-514.4)^{\star \star}$ \\
\hline$-2 \mathrm{LL}$ & 96.22 & 60.67 & 57.88 & 59.83 & 51.22 \\
\hline$R^{2}$ & 16.8 & 45.4 & 50.9 & 59.6 & 61.3 \\
\hline $\begin{array}{l}\mathrm{CC} \\
(\%) \|\end{array}$ & 67.5 & 80.0 & 88.8 & 85.0 & 85.0 \\
\hline
\end{tabular}

${ }^{*} p \leq 0.05$.

${ }^{* \star} p<0.01$.

†CM jump = counter movement jump; SL jump = standing long jump; $1-\mathrm{kg}$ ball throw = 1-kg medicine ball throwing; 3-kg ball throw $=3-\mathrm{kg}$ medicine ball throwing; $20-\mathrm{m}$ sprint $=20-\mathrm{m}$ sprint running; $\% \mathrm{BF}=$ percentage of body fat; END = endomorphic component; MES = mesomorphic component; ECT = ectomorphic component; $\mathrm{LL}=\log$ likelihood; $R^{2}=$ Nagelkerke $R$-squared; $\mathrm{CC}=$ correctly classified.

$\ddagger$ The variable takes the value 1 for girls and 0 for boys.

§The variable takes the value 1 for SG (strength training group) and 0 for CG (control group). $\|$ Cutoff $=0.50$ 
TABLE 4. $\dot{V}_{\mathrm{O}_{2}}$ max gains: Odds ratio of logistic regressions (95\% confidence interval). $\dagger$

\begin{tabular}{ll}
\hline & \multicolumn{1}{c}{$\dot{\mathrm{V}}_{2} \mathrm{max}$} \\
\hline Girls $\ddagger$ & $0.94(0.22-3.9)$ \\
$\%$ BF & $1.24(0.71-2.17)$ \\
END & $0.28(0.02-4.36)$ \\
MES & $1.01(0.32-3.17)$ \\
ECT & $3.84(1.2-12.27)^{\star}$ \\
EG§ & $13.38(3.02-59.27)^{\star \star}$ \\
$-2 \mathrm{LL}$ & 63.976 \\
$R^{2}$ & 61.48 \\
CC $(\%) \|$ & 83.30 \\
\hline
\end{tabular}

${ }^{*} p \leq 0.05$

${ }^{* *} p<0.01$.

$\dagger \% \mathrm{BF}=$ percentage of body fat; $\mathrm{END}=$ endomorphic component; $\mathrm{MES}=$ mesomorphic component; $\mathrm{ECT}=$ ectomorphic component; $\mathrm{LL}=\log$ likelihood; $R^{2}=$ Nagelkerke $R$-squared; $\mathrm{CC}=$ correctly classified.

$\ddagger$ The variable takes the value 1 for girls and 0 for boys. $\S$ The variable takes the value 1 for EG (endurance training group) and 0 for $C G$ (control group).

Cutoff $=0.50$.

participants were barefoot and wore only underwear. Body mass was measured to the nearest $0.1 \mathrm{~kg}$ using a standard digital floor scale (model 841; Seca, Hamburg, Germany). Standing height was assessed with a precision stadiometer to the nearest $0.10 \mathrm{~cm}$ (model 214; Seca). For perimeter measurement, a circumference tape was used (Seca 200). Bicondyle femoral and humeral diameters were assessed (Rosscraft, Campbell 10 Caliper, Canada). The percent body fat from skinfold anthropometry was calculated using a skinfold caliper (Harpenden Skinfold Caliper [British Indicators Ltd., Luton, United Kingdom], range: $0-80 \mathrm{~mm}$, measurement pressure: $10 \mathrm{~g} \cdot \mathrm{mm}^{-2}$ ) following the method described by Slaughter et al. (35). As such, triceps and sub-

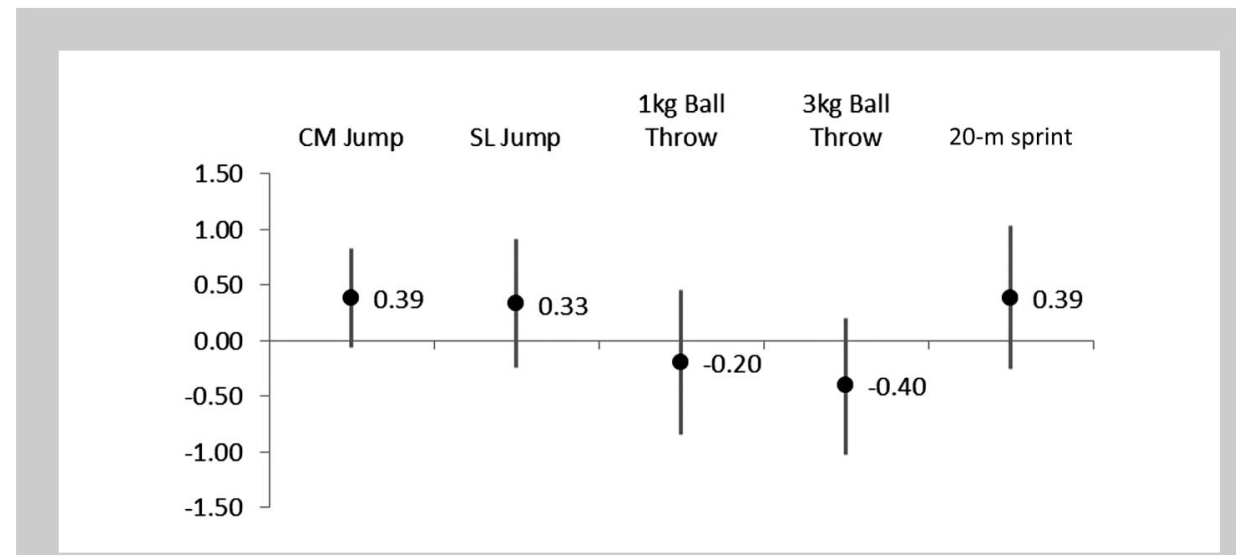

Figure 7. Regression coefficients $\beta$ and $95 \%$ confidence interval of fat mass as predictor of strength gains. 


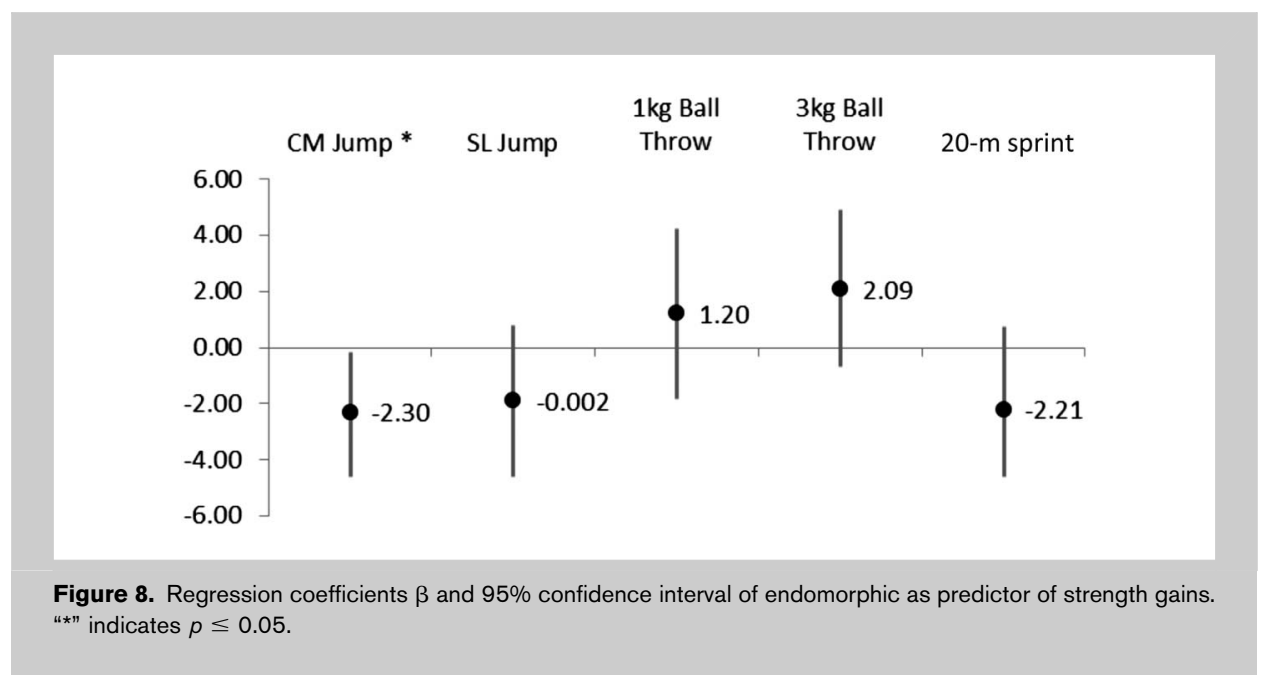

to recorded beeps. The subjects ran between the 2 lines, turning when signaled by the recorded beeps. After about 1 minute, a sound indicates an increase in speed, with the beeps closer together. The beeps sound every minute (level). The standard version with an initial running velocity of $8.5 \mathrm{~km} \cdot \mathrm{h}^{-1}$ and increments of $0.5 \mathrm{~km} \cdot \mathrm{h}^{-1}$ each minute (17) was used. When the participants failed to reach the line on 2 consecutive occasions, they were stopped, and the number of completed 20-m laps was recorded. Estimated

(27). Subjects were seated with the backside of the trunk in touch with a wall. They were required to throw $1 \mathrm{~kg}$ (model VMB-001R; Vinex, Bhalla International- Vinex Sports, Meerut, India, perimeter $0.72 \mathrm{~m}$ ) and $3 \mathrm{~kg}$ (model VMB-001R; Vinex, perimeter $0.78 \mathrm{~m}$ ) medicine balls forward for maximum distance. Hip flexion was not allowed, nor removal of the torso from its position against the wall. Three trials were conducted, and the furthest throw was measured from the wall to initial ground contact ( $\mathrm{ICC}=0.94-0.97$ ).

Twenty-Meter Sprint Running. In a track measuring $20 \mathrm{~m}$ in length, subjects were required to cover the distance in the shortest time they could. Time to run $20 \mathrm{~m}$ was obtained using photocells (Brower Timing System, Fairlee, VT, USA). Three trials were performed, and the best time scored was registered $(\mathrm{ICC}=0.97)$.

Twenty-Meter Multistage Shuttle Run. This test involved continuous running between 2 lines $20 \mathrm{~m}$ apart in time
$\dot{\mathrm{V}}_{2} \max \left(\mathrm{ml} \cdot \mathrm{kg}^{-1} \cdot \mathrm{min}^{-1}\right)$ was calculated by the Léger's equation (17) $(\mathrm{ICC}=0.97)$.

\section{Statistical Analyses}

Standard statistical methods were used for the calculation of the means and SDs. Normality of distribution was checked by applying the Kolmogorov-Smirnov test. The within-subject reliability of endurance and power tests was determined by the ICC. The training related effects in the control and experimental groups were assessed using a paired-samples $t$-test. Binary logistic regression analysis was also carried out to show probabilities/odds ratios (ORs) between somatotypes and performance variables. For each performance variable, a new dichotomous variable was created taking the value 1 when there was a gain from pretraining to posttraining and 0 if no gain occurred between the 2 moments. Statistical analyses were carried out by using the statistical packages for SPSS 15.0 for Windows (SPSS Inc., Chicago, IL, USA). The statistical significance was set at $p \leq 0.05$.

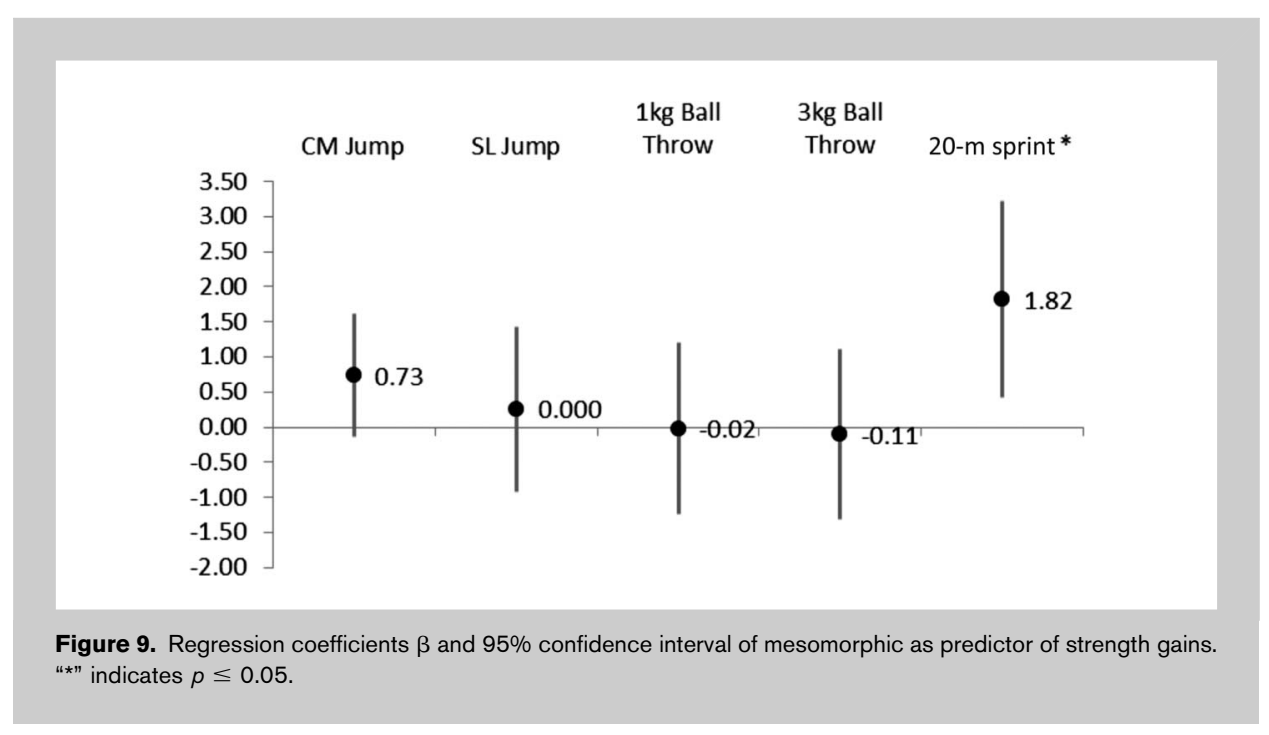

\section{Results}

At baseline, there were no differences between the control and experimental groups for any of the performance tests. After 8-week training, there were improvements in all strength and endurance measures for both boys and girls (Figures 1-6). Training-induced strength gains ranged from 2.90 to $8.30 \%$ in the boys and from 2.25 to $8.10 \%$ in the girls. In both boys and girls, the poorest gains were in the time-at-20 m (Figure 5) and the best ones in the 3-kg medicine ball throwing 


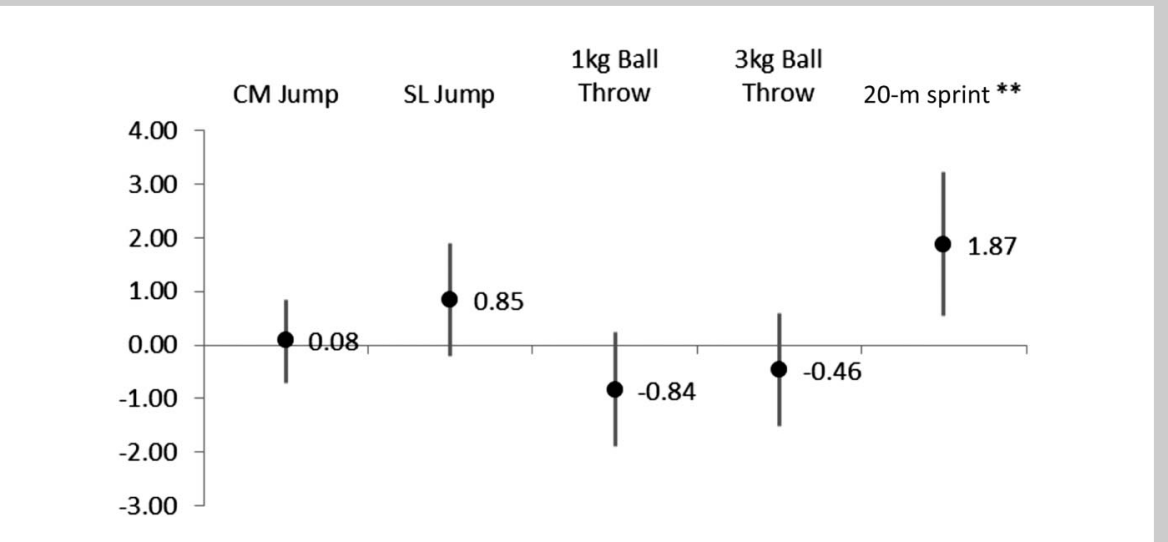

Figure 10. Regression coefficients $\beta$ and $95 \%$ confidence interval of ectomorphic as predictor of strength gains. "**" indicates $p<0.01$.

(Figure 4). The training-induced $\dot{\mathrm{V}}_{2}$ max gains ranged from $3.06 \%$ (girls) to $8.30 \%$ (boys). No significant changes were observed in the CG group ( $p>0.05$ ).

As a result of binary logistic regression analysis, it was observed that the endomorphic component (OR, 0.10; 95\% confidence interval [CI], 0.01-0.85) may have an influence on the vertical jump gains. The 1-unit increase in this component reduces by 10 times the probability of a traininginduced gain. The mesomorphic (OR, 6.15; 95\% CI, 1.5224.88 ) and ectomorphic (OR, 6.52; 95\% CI, 1.71-24.91) components may have an influence on improvements in sprint ability. The 1-unit increase in the mesomorphic component increases by 6.2 times the probability of a traininginduced gain, and the increase by 1 unit in the ectomorphic component increases by 6.5 times the probability of a training-induced gain for this variable (Table 3 ).

Children belonging to the strength training group were 11.7 times more likely to show training-induced horizontal

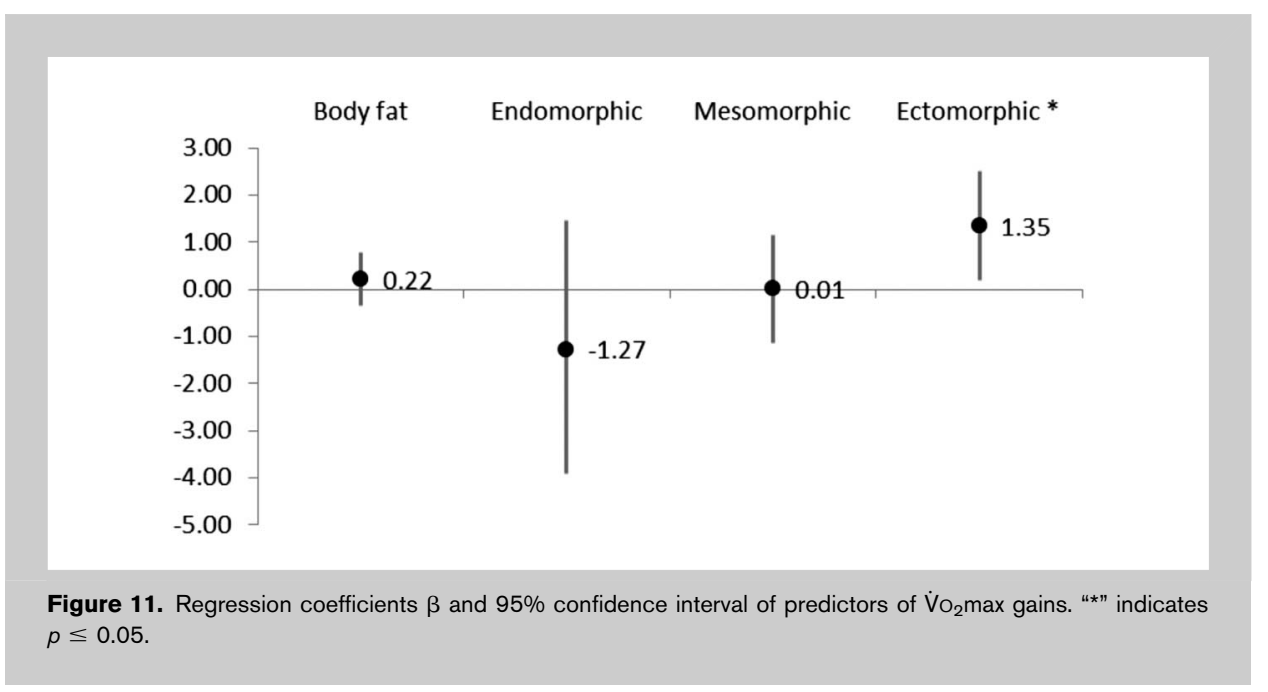

VOLUME 27 | NUMBER 12 | DECEMBER 2013 | jump gains (OR, 11.72; 95\% CI, 2.55-53.83), 23.8 times more likely to show training-induced $1-\mathrm{kg}$ ball throw gains (OR, 23.82; 95\% CI, 4.46-127.07), about 53 times more likely to show training-induced $3-\mathrm{kg}$ ball throw gains (OR, 53.01; 95\% CI, 4.46-127.07), and about 62 times more likely to show training-induced sprint running gains (OR, 61.98; 95\% CI, 7.47-514.4) (Table 3).

Children belonging to the endurance training group were 13.3 times more likely to show training-induced gains in aerobic fitness (OR, 13.38; 95\% CI, 3.02-59.27). The ectomorphic component (OR, 3.84; 95\% CI, 1.20-12.27) showed an influence on aerobic fitness gains. The 1-unit increase in this component increases by 3.84 times the probability of a training-induced gain for this variable (Table 4).

Additionally, it seems that the variable "sex" did not have an influence on training-induced strength or endurance changes (Tables 3 and 4).

Figures 7-11 show the estimated beta coefficients, associated with the predictors of the logit of the probability of gain, for each dependent variable. The estimated ORs of each predictor variable correspond to the exponentiation of each associated beta coefficient. The beta coefficients allow for the analysis of the positive or negative effect of the dependent variables on the probability of gain by the corresponding signal (negative reduces likelihood and positive increases likelihood). Analysis is performed using ORs by comparing these effects with the unit $(>1$ increases likelihood and $<1$ decreases likelihood). Body fat did not influence training-induced explosive strength gains (Figure 7). An increase in endomorphy decreases the likelihood of gain in the vertical jump (Figure 8 ). An increase in mesomorphy and ectomorphy increased the likelihood of gain in sprint running (Figures 9 and 10 , respectively). An increase in ectomorphy increased the likelihood of gain in the aerobic fitness (Figure 11).

\section{Discussion}

The aim of this study was to analyze the influence of body composition and somatotype on the training of explosive 
strength and endurance in prepubescent children aged 10-11 years. The findings indicate that somatotype has an impact on various components of physical performance. Specifically, endomorphy may have a negative influence on vertical jump gains, mesomorphy may have a significant positive influence on sprint running gains, and the ectomorphic component may be positively associated with sprint running and aerobic capacity gains. It does not appear that sex influenced the training-induced adaptations in explosive strength or aerobic capacity. These findings highlight the importance of morphological typology and seem to suggest that the limits imposed by what is a manifestation of genetic determinism, observed from the morphoconstitutional point of view, should not be disregarded because the preponderance of body fat, musculoskeletal development, and relative linearity can be crucial factors affecting training-induced strength and aerobic capacity gains in prepubescent children.

As expected, the strength group improved explosive strength of upper and lower limbs and $20-\mathrm{m}$ sprint performance, indicating that implementation of a strength training program at school can be a positive stimulus to enhance explosive strength in healthy prepubescent children. The current results also showed enhancement in aerobic capacity, highlighting the potential for endurance training programs in untrained boys and girls. These findings were consistent with the results of previous studies conducted with children and adolescents, in which strength and endurance training programs were conducted $(33,34)$.

Despite, the beneficial changes in physical performance endomorphy were negatively associated with traininginduced gains for vertical jump. The body fat associated with endomorphy represents an inert noncontributory load and thus an increased metabolic cost for children (28), making them less efficient in tasks in which the body must be projected (9). On the contrary, the relative linearity associated with ectomorphy (21) had a positive contribution on the training response involving propulsion tasks and cardiorespiratory response. Because of the negative effect of body weight on these tasks, the ectomorphic component has the advantage (15), because it is based on weighting index, that is, the quotient of height by the cube root of body weight (21). Chaouachi et al. (5) also reported the greatest gains in aerobic capacity for individuals with ectomorphy dominance. Mesomorphy had a favorable impact on the training response involving sprint running. This primary component of the somatotype indicates robustness and therefore associates positively with strength and motor performance in general (21). The fundamental role of relative musculoskeletal magnitude on sprint running was also reported by Jakšić and Cvetković (15) in a neural network analysis of somatotype differences related to motor abilities. Regarding the lack of association between the mesomorphy and traininginduced strength gains, it should be taken into account that during preadolescence neural adaptations and intrinsic muscle adaptations are primarily responsible for traininginduced strength gains in this age group $(31,32)$. A better motor coordination of the involved muscle groups may also play a significant role (31). These facts are corroborated by the results of some studies in the literature that reported no significant associations of strength training with increases in gross limb morphology $(31,32)$. There is evidence that by prepuberty there already exists a fairly stable somatotype, pointing to 8 years as the age by which somatotype stability becomes manifest $(21,22)$. However, an analysis to changes in morphological typology of children during growth shows that in prepuberty boys tend to show a slight increase of the mesomorphic values and girls show an increase of the endomorphic and a slight reduction of the ectomorphic values, whereas the mesomorphic component does not change significantly (22); so, the effect of the somatotype on the traininginduced gains can be even more evident in this age group.

Comparison between the 2 sexes revealed no effect on training-induced strength or aerobic fitness adaptations. These data corroborate the results of previous studies conducted with prepubescent children, which reported no significant differences in aerobic training response related to gender (29). Aerobic training increased $\dot{\mathrm{VO}}_{2}$ max in children of both sexes, mediated by an improvement in maximum stroke volume (29). Similar mechanisms, including loading conditions and cardiac morphology, seem to be involved, with both boys and girls, explaining such an improvement (29). According to Vinet et al. (39), during preadolescence there are no significant gender differences in maximal heart rate and arteriovenous oxygen, and although the stroke volume is significantly higher in boys than in girls, when expressed relative to lean body mass, the difference is no longer significant.

The observed similarity of adaptations for boys and girls for explosive strength is also consistent with the findings of previous studies conducted with prepubescent children (18). Training-induced strength gains during and after puberty in males are associated with increases in fat-free mass because of the effect of testosterone on muscle hypertrophy. In contrast, smaller amounts of testosterone in females (resulting from enzymatic conversion of androgenic precursors in the adrenal gland) seem to limit the magnitude of traininginduced strength gains. However, during preadolescence, besides the small muscle mass of girls, boys still present reduced muscle mass because the effects of circulating androgens, particularly testosterone, only manifest themselves at puberty (32).

Our findings suggest that school-based strength and endurance training programs seem to exert a positive impact on both explosive strength and cardiorespiratory fitness for prepubescent children. The effect of adiposity on explosive strength, musculoskeletal magnitude on running speed, and relative linearity on running speed and aerobic capacity seem to be crucial factors related to training-induced adaptations. Additionally, the data suggest that sex does not affect the training-induced changes in strength or aerobic fitness. 
There are several limitations that should be considered: (a) the training period of 8 weeks is brief; (b) different training program designs or different methods of organizing training workouts can lead to different training-induced outcomes; (c) different methods of evaluating pretraining and posttraining muscular strength and aerobic capacity may also lead to data bias; (d) because of the methodological approach (i.e., no electrophysiological measures), it was not possible to clarify the underlying mechanisms responsible for the observed effects.

\section{Practical Applications}

Children aged 10-11 years go through a dynamic developmental period marked by rapid changes in body size, shape, and composition. Children of this age, who share specific physical characteristics, often train together in physical education classes or as part of extracurricular activities. At this age, they attend the second stage of basic education school, and they are in the same training groups at sports clubs or in organized sports activities. Thus, it is useful for trainers and coaches to have a knowledge of the effect that factors such as body fat (which represents an inert load, associated with an increased metabolic cost) and morphological typology (such as the individual's characteristic shape) have on strength and aerobic capacity trainability, at a time of rapid changes such as the prepubertal growth spurt. The knowledge of the effect of body fat on explosive strength gains, musculoskeletal magnitude on the running speed, and relative linearity on running speed and aerobic capacity, as well as the knowledge that sex does not influence traininginduced explosive strength and aerobic fitness, can help to bring the training closer to the individual characteristics, and thus improving the results achieved. Also, this knowledge may be useful in allowing to the trainer to analyze and understand the results obtained in the process of assessment.

\section{ACKNowledgments}

The authors thank all the children who participated in this research. The authors also thank Professor Jason Vescovi for the critical review of the manuscript. The authors have no professional relationships with any companies or manufacturers identified in this study. The results of this study do not constitute endorsement of the product either by the authors or by the National Strength and Conditioning Association. This work was financially supported by FCT under the project PEst-OE/EGE/UI4056/2011, Research Unit for Inland Development, of Polytechnic Institute of Guarda (IPG), by which we appreciate.

\section{REFERENCES}

1. Adam, C, Klissouras, V, Ravassolo, M, Renson, R, Tuxworth, W, Kemper, H, Van Mechelen, W, Hlobil, H, Beunen, G, LevarletJoye, H, and Van Lierde, A. Eurofit: Handbook for the Eurofit Test of Physical Fitness. Rome: Edigraf Editoriale Gráfica, 1988.

2. Anderssen, SA, Cooper, AR, Riddoch, C, Sardinha, LB, Harro, M, Brage, S, and Andersen, LB. Low cardiorespiratory fitness is a strong predictor for clustering of cardiovascular disease risk factors in children independent of country, age and sex. Eur J Cardiovasc Prev Rehabil 14: 526-531, 2007.

3. Centers for Disease Control and Prevention. Physical activity levels among children aged 9-13 years-United States, 2002. Morb Mort Wk Rep 52: 785-788, 2003.

4. Cepero, MR, López, R, Suárez-Llorca, C, Andreu-cabrera, E, and Rojas, FJ. Fitness test profiles in children aged 8-12 years old in Granada (Spain). J Hum Sport Exerc 6: 135-146, 2011.

5. Chaouachi, M, Chaouachi, A, Chamari, K, Chtara, M, Feki, Y, Amri, M, and Trudeau, F. Effects of dominant somatotype on aerobic capacity trainability. Br J Sports Med 39: 954-959, 2005.

6. Chu, D, Faigenbaum, A, and Falkel, J. Progressive Plyometrics for Kids. Monterey, CA: Healthy Learning Publications, 2006.

7. Coleman, KJ, Heath, EM, and Alcala, IS. Overweight and aerobic fitness in children in the United States/Mexico border region. Rev Panam Salud Publica 15: 262-271, 2004.

8. Duke, PM, Litt, IR, and Gross, RT. Adolescents' self-assessment of sexual maturation. Pediatrics 66: 918-920, 1980.

9. Dumith, SC, Ramires, VV, Souza, MA, Moraes, DS, Petry, FG, Oliveira, ES, Ramires, SV, and Hallal, PC. Overweight/obesity and physical fitness among children and adolescents. J Phys Act Health 7: 641-648, 2010

10. Duzgun, I, Kanbur, NO, Baltaci, G, and Aydin, T. The effect of Tanner stage on proprioception accuracy. J Foot Ankle Surg 50: 1115, 2011.

11. Faigenbaum, AD, Kraemer, WJ, Blimkie, CJR, Jeffreys, I, Micheli, LJ, Nitka, M, and Rowland, TW. Youth resistance training: Updated position statement paper from the National Strength and Conditioning Association. J Strength Cond Res 23: S60-S79, 2009.

12. Faigenbaum, AD, Kraemer, WJ, Cahill, B, Chandler, J, Dziados, J, Elfrink, LD, Forman, E, Gaudiose, M, Micheli, L, Nitka, M, and Roberts, S. Youth resistance training: Position statement paper and literature review. J Strength Cond Res 18: 62-75, 1996.

13. Heath, $\mathrm{BH}$ and Carter, JEL. Growth and somatotype patterns of Manus children, territory of Papua and New Guinea: Application of a modified somatotype method to the study of growth patterns. $\mathrm{Am}$ J Phys Anthropol 35: 49-67, 1971.

14. Ignjatović, A, Stanković, R, Radovanović, D, Zivorad, MZ, and Cvecka, J. Resistance training for youths. Facta Universitatis 7: 189196, 2009.

15. Jakšić, D and Cvetković, M. Neural network analysis of somatotype differences among males related to the manifestation of motor abilities. Acta Kinesiologica 3: 107-113, 2009.

16. Kotzamanidis, C. The Effect of plyometric training on running performance and vertical jumping in prepubertal boys. J Strength Cond Res 20: 441-445, 2006.

17. Léger, LA, Mercier, D, Gadoury, C, and Lambert, J. The multistage 20 meter shuttle run test for aerobic fitness. J Sports Sci 6: 93-101, 1988.

18. Lillegard, WA, Brown, EW, Wilson, DJ, Henderson, R, and Lewis, E. Efficacy of strength training in prepubescent to early postpubescent males and females: The effects of gender and maturity, Pediatr Rehabil 1: 147-157, 1997.

19. Linnamo, V, Newton, R, Hakkinen, K, Komi, P, Davie, A, McGuigan, M, and Triplett-McBride, T. Neuromuscular responses to explosive and heavy resistance loading. J Electromyogr Kinesiol 10: 417-424, 2000.

20. Linthorne, NP. Analysis of standing vertical jumps using a force platform. Am J Physics 69: 1198-1204, 2001.

21. Malina, R and Bouchard, C. Growth Maturation and Physical Activity. Champaign, IL: Human Kinetics, 1991.

22. Malina, R, Bouchard, C, and Bar-Or, O. Growth, Maturation and Physical Activity. Champaign, IL: Human Kinetics, 2004. 
23. Marfell-Jones, M, Olds, T, Stewart, A, and Carter, L. International Standards for Anthropometric Assessment. Potchefstroom, South Africa: ISAK, 2006.

24. Marques, MC, Zajac, A, Pereira, A, and Costa, AM. Strength training and detraining in different populations: Case studies. J Hum Kinet Special Issue: 7-14, 2011.

25. Marshall, WA and Tanner, JM. Variations in the pattern of pubertal changes in girls. Arch Dis Child 44: 291-303, 1969.

26. Matton, L, Duvigneaud, N, Wijndaele, K, Philippaerts, R, Duquet, W, Beunen, G, Claessens, AL, Thomis, M, and Lefevre, J. Secular trends in anthropometric characteristics, physical fitness, physical activity, and biological maturation in Flemish adolescents between 1969 and 2005. Am J Hum Biol 19: 345-357, 2007.

27. Mayhew, JL, Ware, JS, Johns, RA, and Bemben, MG. Changes in upper body power following heavy-resistance strength training in college men. Int J Sports Med 18: 516-520, 1997.

28. Norman, AC, Drinkard, BD, McDuffie, JR, Ghorbani, S, Yanoff, LB, and Yanovski, JA. Influence of excess adiposity on exercise fitness and performance in overweight children and adolescents. Pediatrics 115: e690-e696, 2005.

29. Obert, P, Mandigouts, S, Nottin, S, Vinet, A, N'Guyen, LD, and Lecoq, AM. Cardiovascular responses to endurance training in children: Effect of gender. Eur J Clin Invest 33: 199-208, 2003.

30. Ortega, FB, Tresaco, B, Ruiz, JR, Moreno, LA, Matillas, M, Mesa, JL, Warnberg, J, Bueno, M, Tercedor, P, Gutiérrez, A, and Castillo, MJ. Cardiorespiratory fitness and sedentary activities are associated with adiposity in adolescents. Obesity (Silver Spring) 15: 1589-1599, 2007.

31. Ozmun, J, Mikesky, A, and Surburg, P. Neuromuscular adaptations following prepubescent strength training. Med Sci Sports Exerc 26: 510-514, 1994.
32. Ramsay, J, Blimkie, C, Smith, K, Garner, S, Macdougall, J, and Sale, D. Strength training effects in prepubescent boys. Med Sci Sports Exerc 22: 605-614, 1990.

33. Sandbakk, $\varnothing$, Welde, B, and Holmberg, HC. Endurance training and sprint performance in elite junior cross-country skiers. J Strength Cond Res 25: 1299-1305, 2011.

34. Santos, A, Marinho, DA, Costa, AM, Izquierdo, M, and Marques, MC. The effects of concurrent resistance and endurance training follow a detraining period in elementary school students. J Strength Cond Res 26: 1708-1716, 2012.

35. Slaughter, MH, Lohman, TG, Boileau, RA, Horswill, CA, Stillman, RJ, VanLoan, MD, and Bemben, DA. Skinfold equations for estimation of body fatness in children and youth. Hum Biol 60: 709-723, 1988

36. Strong, W, Malina, R, Blimkie, C, Daniels, S, Dishman, R, Gutin, B, Hergenroeder, A, Must, A, Nixon, P, Pivarnik, J, Rowland, T, Trost, S, and Trudeau, F. Evidence based physical activity for school-age youth. J Pediatr 146: 732-737, 2005.

37. Taanila, H, Hemminki, A, Suni, J, Pihlajamäki, H, and Parkkari, J. Low physical fitness is a strong predictor of health problems among young men: A follow-up study of 1411 male conscripts. Oxford, NY: BMC Public Health 11: 590, 2011.

38. Tanner, JM. Growth at Adolescence, Oxford: Blackwell Scientific Publications, 1962.

39. Vinet, A, Mandigout, S, Nottin, S, Nguyen, L, Lecoq, N, Courteix, D, and Obert, P., Influence of body composition, hemoglobin concentration, and cardiac size and function of gender differences on maximal oxygen uptake in prepubertal children. Chest 124: 1494-1499, 2003.

40. World Health Organization (WHO). Global Recommendations on Physical Activity for Health. Geneva, Switzerland: World Health Organization, 2010. 